\title{
Pins and needles in the groin: an incidental finding of retained needle fragments in an intravenous drug user
}

\author{
Joshua Gladman
}

Central and North West London NHS Foundation Trust, London, UK

\section{Correspondence to Dr Joshua Gladman,} joshua.gladman@nhs.net

Accepted 23 January 2019

\section{SUMMARY}

A female intravenous drug user was reviewed in A\&E following a deliberate overdose. After claiming to have swallowed a razor blade, an abdominal radiograph was performed; this showed a linear metallic density projected over the right side of the pelvis, eventually identified as a needle fragment. Subsequent CT imaging revealed three additional needles situated within the groin. Duplex assessment also identified bilateral arteriovenous fistulae. The patient remained asymptomatic and was managed conservatively. She could recall several occasions when a needle had broken while injecting. This scenario was more likely if the needle had been used many times previously, causing it to become blunt and bent. There are cases reported of adverse patient outcomes secondary to broken needle fragments but awareness among medical professionals remains poor.

\section{BACKGROUND}

Broken and retained needle fragments are a hidden and under-recognised problem and present potential risk to both intravenous drug users and clinicians. ${ }^{1}$ This case report describes a patient who was found to have four needle fragments retained within

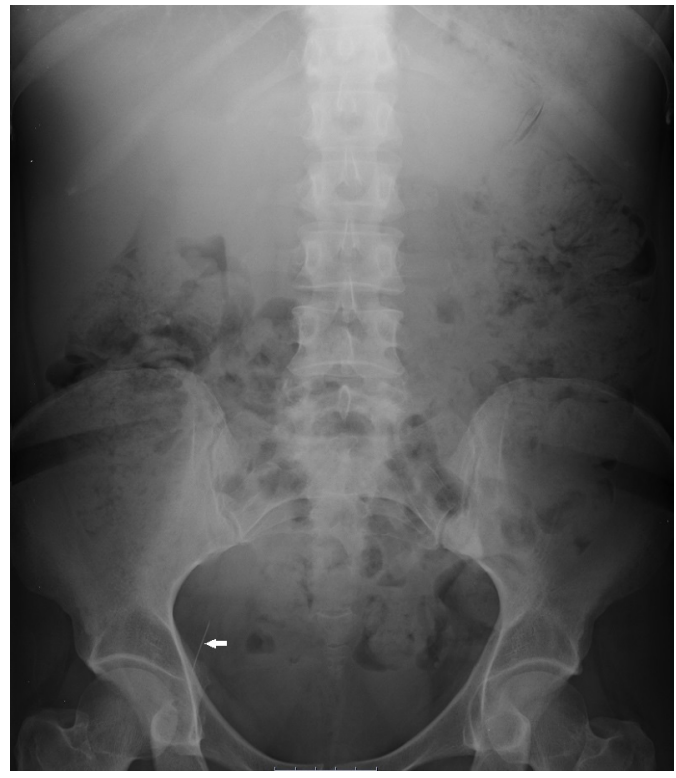

Figure 1 Plain abdominal radiograph featuring a linear metallic density (arrowed) projected over the right side of the pelvis. her groin and includes imaging from her hospital admission and her account of how this happened.

\section{CASE PRESENTATION}

A woman in her forties with a long history of intravenous drug abuse was taken to A\&E following a deliberate overdose. She responded well to treatment but, aggravated by the presence of the police, claimed to have swallowed a razor blade fragment while in the hospital toilets. She reported vomiting about $30 \mathrm{~s}$ afterwards, but this vomit was not inspected. A radiograph of the abdomen was performed and this revealed a linear metallic density projected over the right side of the pelvis (figure 1). This structure was assumed to be the swallowed foreign body and thus the patient was admitted to hospital to monitor for complications and await its safe passage.

A second abdominal radiograph 48 hours later showed the position of the metallic foreign body to be unchanged. The case was discussed with the surgical team who felt that it was stuck in the region of the ileocaecal valve. They advised that that the foreign body would continue to pass through the bowel and to perform further abdominal imaging 24 hours later. Throughout this time, the patient remained stable, with no abdominal discomfort or rectal bleeding.

It was not until after the third abdominal radiograph that the true clinical picture became clear. The position of the foreign body remained unchanged and the images were discussed with the radiology team. They were clear that the object was not lying within the bowel and that by appearance it was more likely to represent a needle. The patient had already admitted that her preferred injection site for heroin was the groin and on subsequent questioning she recalled having had a needle snap off while injecting on several separate occasions. A CT scan of the pelvis was ordered and this demonstrated a $25 \mathrm{~mm}$ metallic foreign body in the right external iliac vein and three further metallic foreign bodies within the left groin (figure 2). Since one needle was found so close to a large vein, an opinion was sought from the vascular surgery team. They arranged for duplex assessment of the relevant vasculature but could not identify anything within the vein. Of note, the patient had formed bilateral arteriovenous fistulae between the common femoral artery and vein secondary to chronic intravenous drug use. 


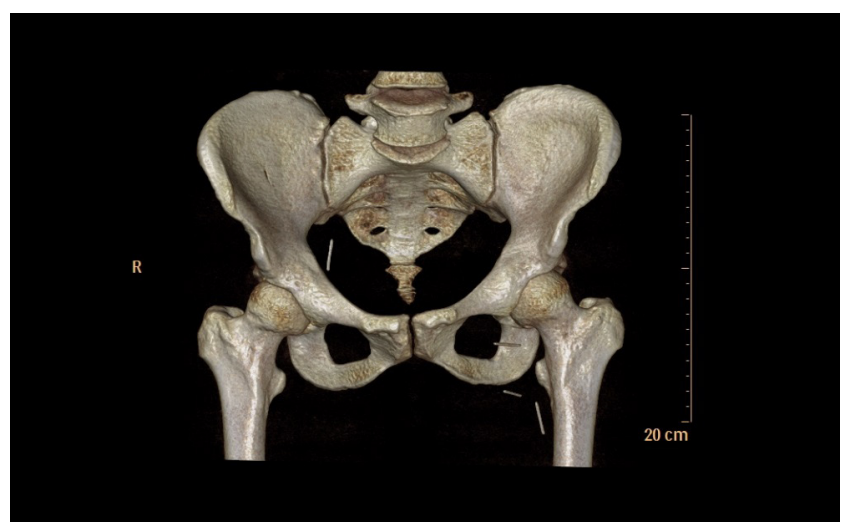

Figure 2 3D image generated from a non-contrast CT scan of the pelvis showing four needle fragments. The fragment on the right represents the metallic foreign body visible in the abdominal radiograph.

It was interesting to talk to the patient about the circumstances of her drug use and why the needles had broken while being used for injection. She reported that it would occur most frequently over a weekend when her local pharmacy and needle exchange programme were closed, leading her to reuse the same 'pin' as it became increasingly blunt. If it became bent, she would bend it back into shape until eventually, while searching for a vein, the syringe would become light in her hand and when withdrawn would be missing most of the needle.

\section{OUTCOME AND FOLLOW-UP}

The patient remained asymptomatic and was therefore managed conservatively with the needles left in situ. She received inpatient treatment for her substance misuse and mental health issues prior to discharge.

\section{DISCUSSION}

With hindsight, it is tempting to feel that the correct diagnosis could have been established earlier. Certainly, this case highlights the perils of becoming too focused on one particular detail of a history, in this instance the reported swallowing of a razor blade, rather than considering the broader clinical picture. It is likely that the patient vomited out the razor blade almost immediately since no evidence of it was ever identified on imaging. There is also a lack of awareness among clinicians of the phenomenon of retained needle fragments, even though this appears to represent a relatively common problem for intravenous drug users. ${ }^{1}$ The consequences can be far from benign: cases of needle embolism have been reported following injection into the femoral vein. ${ }^{2}$ The dangers posed by retained needle fragments to clinicians have also been discussed previously, for example in the context of incising and draining an abscess using blunt dissection with a gloved finger. ${ }^{34}$ Equally, there are case reports that document patients who have retained large numbers of acupuncture needles over many years without any serious consequences. ${ }^{5} 6$ The clinical picture in this instance became far clearer once direct discussion occurred between the clinical teams involved, and once input was sought from a radiologist. The radiologist was able to look at the images dispassionately without trying to fit them to the attention-grabbing, but perhaps ultimately misleading, narrative of a swallowed razor blade. This form of confirmation bias is something to be wary of in the future when seeking to avoid clinical errors.

Allowing multiple needle fragments to collect inside her groin without further action demonstrates a significant degree of self-neglect on the part of the patient. Previous studies have found that similar behaviour is common among intravenous drug users: $96 \%$ of clients at a Glasgow needle-exchange reported a current injecting-related problem and yet $73 \%$ had not sought any treatment. Reasons for this include the normalisation of such problems among this population and the perception that they would be wasting the time of healthcare professionals, often reinforced by past experiences. The patient here described having mentioned to a doctor that she had lost a needle within her groin; however, she had been disbelieved and was thus deterred from mentioning it again. This anecdote highlights the importance of improved awareness of this issue among clinical staff.

It is ultimately from her psychiatric and substance misuse problems that the physical health issues of this patient stem. It is therefore important to consider the thoughts and motivations that underpin the chaotic lifestyle and care-seeking behaviour outlined in this case report. The patient initially presented following a drug overdose, a significant cause of premature mortality among intravenous drug users. ${ }^{8}$ On speaking to her, it became clear that, while the overdose was deliberate, she had not intended nor wished to die. Her reasons were complex and multifactorial but in part it offered a means of coping with the psychological distress associated with a custody battle over her son, who had been placed in the care of the patient's sister. By swallowing, or claiming to have swallowed, a razor blade fragment once in A\&E, the patient secured a hospital admission and thus temporarily avoided being returned to prison by awaiting police officers, having breached the terms of her parole for a burglary offence. It provided a chaotic means by which the patient could exert some form of control over her environment. Even though the self-harm may primarily have been motivated by secondary gain, such acts can nonetheless pose great risk to patients. ${ }^{9}$ In this instance, the behaviour was repeated with tragic inevitability: prior to her discharge from hospital and aware of the police officers once again waiting for her, the patient tied a ligature around her neck. Thankfully, she was not seriously harmed.

Reflecting on this case, it is easy to feel misled and manipulated by the patient. At a personal level, having had several long and heartfelt conversations with her about her personal circumstances, it is difficult to reconcile the empathy these conversations evoked with the possibility of being used simply to avoid arrest. However, I believe that her psychological distress was genuine and that her presentation, while complicated and driven by competing interests, did reflect a need for psychiatric help. Conversely, the patient herself may have felt deceived by the team managing her care since, for reasons of safety, she was not informed prior to discharge that the police would be waiting to escort her from the unit. This experience, and past experiences like it, will influence how the patient interacts with healthcare providers in the future.

\section{Learning points}

Retained needle fragments may be found within intravenous drug users at sites of injection.

- These fragments appear as artefact on imaging and can be mistaken for other foreign objects.

- Needle fragments can cause complications to patients and present a risk of injury to clinicians.

- Ready access to needle-exchange programmes may reduce the risk of this presentation.

- Self-neglect and chaotic care-seeking behaviours are barriers to the treatment of intravenous drug users with physical health problems. 
Contributors JG (corresponding author) completed the planning, literature search and write-up of this case report.

Funding The authors have not declared a specific grant for this research from any funding agency in the public, commercial or not-for-profit sectors.

Competing interests None declared.

Patient consent Obtained.

Provenance and peer review Not commissioned; externally peer reviewed.

\section{REFERENCES}

1 Norfolk GA, Gray SF. Intravenous drug users and broken needles—a hidden risk? Addiction 2003;98:1163-6.

2 Monroe EJ, Tailor TD, McNeeley MF, et al. Needle embolism in intravenous drug abuse. Radiol Case Rep 2012;7:714.
3 Blumstein H, Roberts JR. Retained needle fragments and digital dissection. N Eng/ J Med 1993;328:1426.

4 Williams MF, Eisele DW, Wyatt SH. Neck needle foreign bodies in intravenous drug abusers. Laryngoscope 1993;103:59-63.

5 Galbraith PJ, Richardson ML. Permanently retained acupuncture needles: radiographic findings and case report. Radio/ Case Rep 2006;1:120-2.

6 Lazarow F, Andrews RH, Revels J, et al. Migration of innumerable chronically retained acupuncture needles. Radio/ Case Rep 2017;12:546-8.

7 Morrison A, Elliott L, Gruer L. Injecting-related harm and treatment-seeking behaviour among injecting drug users. Addiction 1997;92:1349-52.

8 Hickman M, Carnwath Z, Madden P, et al. Drug-related mortality and fatal overdose risk: pilot cohort study of heroin users recruited from specialist drug treatment sites in London. J Urban Health 2003;80:274-87.

9 Jeglic EL, Vanderhoff HA, Donovick PJ. The function of self-harm behavior in a forensic population. Int J Offender Ther Comp Criminol 2005;49:131-42.

Copyright 2019 BMJ Publishing Group. All rights reserved. For permission to reuse any of this content visit

https://www.bmj.com/company/products-services/rights-and-licensing/permissions/

BMJ Case Report Fellows may re-use this article for personal use and teaching without any further permission.

Become a Fellow of BMJ Case Reports today and you can:

- Submit as many cases as you like

- Enjoy fast sympathetic peer review and rapid publication of accepted articles

- Access all the published articles

- Re-use any of the published material for personal use and teaching without further permission

For information on Institutional Fellowships contact consortiasales@bmjgroup.com

Visit casereports.bmj.com for more articles like this and to become a Fellow 